\title{
WERE URBAN COWBOYS ENOUGH TO CONTROL COVID-19? LOCAL SHELTER-IN-PLACE ORDERS AND CORONAVIRUS CASE GROWTH
}

\author{
Dhaval M. Dave \\ Andrew I. Friedson \\ Kyutaro Matsuzawa \\ Joseph J. Sabia \\ Samuel Safford \\ Working Paper 27229 \\ http://www.nber.org/papers/w27229

\section{NATIONAL BUREAU OF ECONOMIC RESEARCH \\ 1050 Massachusetts Avenue \\ Cambridge, MA 02138} \\ May 2020
}

Sabia acknowledges research support from the Center for Health Economics \& Policy Studies at San Diego State University, including grant funding received from the Charles Koch Foundation and Troesh Family Foundation. The views expressed herein are those of the authors and do not necessarily reflect the views of the National Bureau of Economic Research.

NBER working papers are circulated for discussion and comment purposes. They have not been peer-reviewed or been subject to the review by the NBER Board of Directors that accompanies official NBER publications.

(C) 2020 by Dhaval M. Dave, Andrew I. Friedson, Kyutaro Matsuzawa, Joseph J. Sabia, and Samuel Safford. All rights reserved. Short sections of text, not to exceed two paragraphs, may be quoted without explicit permission provided that full credit, including $\odot$ notice, is given to the source. 
Were Urban Cowboys Enough to Control COVID-19? Local Shelter-in-Place Orders and Coronavirus Case Growth

Dhaval M. Dave, Andrew I. Friedson, Kyutaro Matsuzawa, Joseph J. Sabia, and Samuel Safford NBER Working Paper No. 27229

May 2020

JEL No. H75,I18,R0

\section{ABSTRACT}

One of the most common policy prescriptions to reduce the spread of COVID-19 has been to legally enforce social distancing through state or local shelter-in-place orders (SIPOs). This paper is the first to explore the comparative effectiveness of early county-level SIPOs versus later statewide mandates in curbing COVID-19 growth. We exploit the unique laboratory of Texas, a state in which the early adoption of local SIPOs by densely populated counties covered almost two-thirds of the state's population prior to Texas's adoption of a statewide SIPO on April 2, 2020. Using an event study framework, we document that countywide SIPO adoption is associated with a 14 percent increase in the percent of residents who remain at home full-time, a social distancing effect that is largest in urbanized and densely populated counties. Then, we find that in early adopting counties, COVID-19 case growth fell by 19 to 26 percentage points twoand-a-half weeks following adoption of a SIPO, a result robust to controls for county-level heterogeneity in outbreak timing, coronavirus testing, and border SIPO policies. This effect is driven nearly entirely by highly urbanized and densely populated counties. We find that approximately 90 percent of the curbed growth in COVID-19 cases in Texas came from the early adoption of SIPOs by urbanized counties, suggesting that the later statewide shelter-in-place mandate yielded relatively few health benefits.

Dhaval M. Dave

Bentley University

Department of Economics

175 Forest Street, AAC 195

Waltham, MA 02452-4705

and IZA

and also NBER

ddave@bentley.edu

Andrew I. Friedson

Department of Economics

University of Colorado Denver

Lawrence Street Center 460T

Campus Box 181

P.O. Box 173364

Denver, CO 80217-3364

andrew.friedson@ucdenver.edu

Kyutaro Matsuzawa

Center for Health Economics

and Policy Studies

San Diego State University

San Diego, CA

qmatsuzawa@gmail.com
Joseph J. Sabia

San Diego State University

Department of Economics

Center for Health Economics

\& Policy Studies

5500 Campanile Drive

San Diego, CA 92182

and IZA \& ESSPRI

jsabia@sdsu.edu

Samuel Safford

Center for Health Economics

and Policy Studies

San Diego, CA

safford.samuel@gmail.com 


\section{Motivation}

The first case of COVID-19 in the United States was confirmed on January 20, 2020 in Washington State (Holshue et al. 2020). The disease rapidly spread among the U.S. population over the following months, with the U.S. becoming the country with the most confirmed cases of COVID-19 on March 26, 2020 (Johns Hopkins University 2020). As of May 1, 2020, COVID19 was confirmed to have killed over 59 thousand Americans, surpassing the American death toll due to the Vietnam War (Defense Casualty Analysis System 2008; Johns Hopkins University 2020).

Public health responses to the COVID-19 pandemic have centered around a variety of non-pharmaceutical interventions (NPIs) such as closing schools, closing restaurants and other businesses, banning larger gatherings, and issuing blanket shelter-in-place orders (SIPOs). While the federal government has the ability to make disaster declarations, offer public health recommendations, and direct resources (for example, the federal government can force industries to produce needed medical supplies under the Defense Production Act), the power to enact most NPIs rests with state and local governments.

The efficacy of NPIs at slowing the spread of COVID-19 is the subject of a growing literature. National studies such as Dave et al. (2020) and Courtemanche et al. (2020a), as well as studies of state-specific policy interventions in California (Friedson et al. 2020) and in Kentucky (Courtemanche et al. 2020b) have shown sizable reductions in the growth rate of COVID-19 cases due to certain NPIs, in particular SIPOs. ${ }^{1}$

\footnotetext{
${ }^{1}$ Courtemanche et al. (2020a) and Courtemanche et al. (2020b) found no improvement in case growth rates from school closures or bans on large gatherings, modest improvements from restaurant and entertainment center closures and large improvements from SIPOs. Friedson et al. (2020) and Dave et al. (2020) documented large improvements from SIPOs.
} 
SIPOs carry legal penalties for failure to comply with "social distancing” behavior, i.e. maintaining physical distance from individuals outside of one’s household (Allday 2020). Social distancing is a primary recommendation for slowing the spread of COVID-19 from the Centers for Disease Control and Prevention along with other contagion-reducing activities such as hand washing and wearing face coverings in public (Centers for Disease Control 2020). SIPOs have been empirically demonstrated to improve social distancing by reducing the frequency that individuals travel outside of their homes using anonymized cell phone location data (Dave et al. 2020; Friedson et al. 2020).

As COVID-19 is a disease that is spread via close proximity to others, and can be spread by asymptomatic individuals (Bai et al. 2020; Pan et al. 2020; Rothe et al. 2020), the speed at which the disease spreads in the absence of intervention will depend on how frequently individuals come in close contact. Thus, the speed of transmission in a given location will be in part a function of how densely populated a location is. This means that SIPOs (and other NPIs) could vary greatly in their efficacy based on the density of the local population. Indeed, Dave et al. (2020) showed that SIPOs were much more effective at slowing the spread of COVID-19 in states that had higher average population density relative to states with lower average population density.

State level population density, however, does not capture the large amount of variation in population density across locations within a state. In 2010, metropolitan statistical areas had an average population density of 282.9 persons per square mile, whereas micropolitan statistical areas had an average population density of 82.5 persons per square mile, and locations outside of core-based statistical areas (i.e. rural locations) had an average population density of 42.0 persons per square mile (Wilson et al. 2012). Thus, blanket NPIs that uniformly cover a variety 
of locations within a single state could have significant variation in their ability to slow the spread of disease.

This leads to an important policy question: is it possible to judiciously apply local SIPOs only in more densely populated locations, and still receive the majority of their public health benefits without a blanket statewide order across heterogeneously populated jurisdictions? Given that SIPOs may have important job-related costs (Baek et al. 2020), understanding how to achieve public health benefits at the least cost is important.

In order to empirically answer this question, it is necessary to narrow to a within-state analysis, capitalizing on natural experiments occurring within states that enacted statewide SIPOs, but also had a substantial number of localities enacting local orders prior to the state SIPO. Moreover, given the incubation period of COVID-19 of approximately 5-12 days (Lauer et al. 2020), a sufficiently lengthy time window is needed between when the earliest localities enacted their orders and the later statewide order, to disentangle the effects of each. Our focus on the roles of population density and urbanicity in potentially reinforcing the effects of social distancing measures also requires that early local orders are adopted across a slate of urbanized, non-urbanized, populated, and sparse counties.

These considerations direct our main analysis to the state of Texas, which has a number of features that make it an ideal laboratory for studying the efficacy of SIPOs based on population density. Texas enacted a statewide SIPO, but did so quite late relative to other states. California, which enacted the first statewide SIPO, did so on March 19th, whereas Texas enacted its statewide SIPO on April 2nd, the 34th state to do so. ${ }^{2}$ However, 85 of Texas' 254 counties enacted their own county-level SIPOs prior to the statewide order, with 34 of the county orders

\footnotetext{
${ }^{2}$ Texas is tied with Maine as the $34^{\text {th }}$ state to enact a statewide SIPO.
} 
enacted over a week prior to the statewide order - the most, by far, out of any other statewide SIPO-enacting state. Of these 34 early-adopting counties, 18 had urbanicity rates (percentage of population living in urbanized areas or urban clusters) of greater than 75 percent and 10 had urbanicity rates of over 90 percent, both the highest among statewide SIPO states with early adopting counties. Moreover, 18 of 34 early-adopting Texas counties had population densities greater than 150 persons per square mile, ${ }^{3}$ and 5 had population densities greater than 1,000 persons per square mile, each of which constituted the largest number of early-adopting counties among statewide-SIPO adopting states.

Relatedly, in terms of coverage, Texas also had the greatest flurry of activity with respect to the early local orders; these early local orders covered approximately two-thirds (66 percent) of the state's population a week prior to the statewide SIPO order, a share greater than any other state. Thus, these county SIPO policies created important variation both in the timing of local SIPOs as well as the density of the local population impacted by these local orders, both critical in answering our research questions. ${ }^{4}$

By leveraging these differences, as well as daily data on both social distancing behavior (via anonymized cell phone location data) and COVID-19 cases, we demonstrate that (1) countylevel SIPOs enacted in Texas were somewhat more effective at eliciting social distancing behavior in more densely population areas, and (2) county-level SIPOs in Texas were immensely more effective at slowing the spread of the disease in more densely populated areas.

\footnotetext{
${ }^{3}$ The 18 counties with population densities greater than 150 persons per square mile were not identical to the 18 counties with population densities greater than 150 persons per square mile. For example, among the "high urbanicity" counties that were not classified as "high population density counties" (using the 150 persons per square population cutoff) were Hood County, Starr County, Stephens County, Val Verde County, and Willacy County. Those counties with more than 150 persons per population with urbanicity rates less than 75 percent were Ellis, Hays, Hunt, Kaufman, and McLennan counties.

${ }^{4}$ Texas provided the most jurisdiction-level variation with 34 counties enacting a local order at least 7 days prior to the statewide order, more than double that of the state with the next most variation (Missouri), which covered less of the state population than Texas.
} 
These results have important implications for public health policies moving forward. As policies such as SIPOs may have important economic costs associated with them (Baek et al. 2020), if government can move from one-size-fits-all policies, such as statewide SIPOs to more nuanced policies based on the characteristics of each location, such as SIPOs targeted at more densely populated areas, it may be possible to improve public welfare without making large sacrifices to public health.

\section{Data and Methods}

\subsection{Social Distancing Data}

To measure county-level social distancing, we utilize data from SafeGraph, Inc., following Friedson et al. (2020) and Dave et al. (2020). These data are generated from 45 million anonymized GPS cell phone pings that can be used to measure the degree of social distancing among a local population, in this case at the county level.

A cell phone’s "home” is defined as the 153- by 153-meter location where the cell phone is pinged most frequently during the hours between $6 \mathrm{pm}$ and $7 \mathrm{am}$. We then measure the percent of the cell phones (and presumably residents who own said cell phones) within a county that spend a given day within the "home" location. This margin of social distancing, measuring allday stay-at-home behavior, is not based on total distance traveled, and therefore also enables better comparisons between rural and urban counties than other measures that can be calculated with SafeGraph. ${ }^{5}$

On March 18, 2020, about five days prior to the adoption of a SIPO in early-adopting urban counties (as there is some variation in implementation dates between these counties), 31.8

\footnotetext{
${ }^{5}$ It is still possible that there is a degree of undercounting in this measure for rural residences, as they are more likely to be larger than 153 - by 153-meters than urban residences.
} 
percent of residents had stayed at home full-time, subsequently increasing to 41.2 percent (by 9.4 percentage points) by March 30. To contrast, five days prior to the statewide SIPO, 34.9 percent of residents in counties that had not adopted a local SIPO — counties with an average urbanicity rate under 20 percent — sheltered-in-place full-time. By five days following the statewide order, 37.6 percent did so (an increase of only 2.7 percentage points). This pattern of findings suggests that local SIPOs may have had larger effects for early adopting urban counties relative to nonadopting counties. We return to these findings below, where we test these relationships formally.

\subsection{COVID-19 and Policy Data}

We draw county-level daily data on reported COVID-19 cases in Texas from March 8, 2020 through April 28, 2020 for our analyses. These data are compiled by county public health departments, reported to the Centers for Disease Control and Prevention, and made public via the Kaiser Family Foundation. ${ }^{6}$ By April 28, 2020, there were a total of 1,012,878 confirmed reported coronavirus cases in the United States, 26,865 (2.7 percent) of which were in the State of Texas. Over the period from March 8 through April 28, there was an average of 34.5 new cases per state-day. ${ }^{7}$

Local policy data on SIPOs, as well as data on local non-essential business closures and emergency decrees were collected by the Center for Health Economics \& Policy Studies at San Diego State University. As noted above, a shelter-in-place order (SIPO) is one of the most

\footnotetext{
${ }^{6}$ These data can be obtained here: https://github.com/nytimes/covid-19-data

${ }^{7}$ Over this period, there were a total of 53,034 COVID-19 deaths, 738 (1.4 percent) of which were in the State of Texas. Appendix Figure 1 shows coronavirus case growth statewide for Texas over our sample window, and across early adopting counties (which enacted a SIPO at least 7 days prior to the state order on April $2^{\text {nd }}$ ), later adopting counties (that issued a SIPO prior to but within 6 days of the statewide order), and non-adopting counties (that were bound by the statewide order).
} 
restrictive emergency measures taken by a jurisdiction in order to combat a current emergency. These orders require all local residents and visitors to stay-at-home or shelter-in-place for all but essential activities. While there are a limited number of jurisdictions that issued SIPOs to targeted populations (i.e. elderly, juveniles, recent international travelers), full SIPOs are imposed on all present in a county or state. SIPOs are also accompanied by a full non-essential business closure. Data on state and county SIPOs are collected using information compiled by the National Association of Counties (2020), Mervosh et al. (2020), Friedson et al. (2020), and our own searches of official county websites, county court records, local news agencies, and gubernatorial executive orders and proclamations.

Data on non-essential business closures (NEBCOs) are also collected via searches of official county governmental websites (county executive or legislative branches, including county departments of health), county court records, local news agencies, and state records of gubernatorial executive orders or proclamations. NEBCOs primarily serve to mandate the closure of all businesses not deemed to be essential for day-to-day operations. Common essential businesses regularly include grocery stores, gas stations, funeral homes, some healthcare facilities, pharmacies, veterinarians, and financial institutions (including banks).

We also collect information on county emergency decrees through searches of official county websites, county court records, local news agencies, and the National Association of Counties (2020). These declarations are formal proclamations issued by a jurisdiction's chief public official (i.e. Mayors, County Judges, County Executives, or Governors) announcing that a current or impending crisis will require additional action that exceeds a county or (state's) standard resource response capabilities. Such declarations typically include language invoking emergency powers and operations for a pre-determined period of time, which can then be 
extended if deemed necessary. These powers commonly include the authorization for a county to request all assistance available from higher jurisdictions, as well as the activation of a local Public Health or Emergency Management agency to take actions to protect the public health.

In addition, we collect data on average temperature in the county and whether there was measurable precipitation in the county as weather conditions may on the margin influence individual compliance with social distancing. These data are drawn from the National Centers for Environmental Information at the National Oceanic and Atmospheric Administration. ${ }^{8}$

Finally, we collect information on the urbanicity (the percent of a county's population that lives within urbanized areas or urban clusters) and population density of Texas counties from the 2010 Census. ${ }^{9}$ The median urbanicity rate of a Texas county was 46 percent and the median population density rate was 22 persons per square mile.

\subsection{Methods}

The aim of this study is to assess whether public health effects accrued to local jurisdictions adopting a shelter-in-place order early, in advance of the statewide order, and whether any potential benefits were magnified in such early-adopting jurisdictions that had a more tightly packed population. Our empirical analysis proceeds in a stepwise manner to address these questions.

We begin by estimating the first-order relationship between county-level SIPO adoption and social distancing through a difference-in-differences identification strategy:

\footnotetext{
${ }^{8}$ These data are at: https://www.ncdc.noaa.gov/cdo-web/. Appendix Table 1 presents the sample means for all variables.

${ }^{9}$ This includes urbanized Areas (UAs) of 50,000 or more people or urban clusters of at least 2,500 and less than 50,000 people. These data are available at: https://www.census.gov/programs-surveys/geography/guidance/geoareas/urban-rural/2010-urban-rural.html
} 


$$
\text { PCTHOME } E_{\mathrm{ct}}=\gamma_{0}+\gamma_{1} \text { SIPO }_{\mathrm{ct}}+\mathbf{X}_{\mathrm{ct}} \boldsymbol{\beta}_{2}+\alpha_{\mathrm{c}}+\tau_{\mathrm{t}}+\varepsilon_{\mathrm{ct}}
$$

where $P C T H O M E_{\mathrm{cs}}$ measures the share of the county population that remained at home full-time, $S I P O_{\mathrm{ct}}$ is an indicator for whether a shelter-in-place order was in effect in county $c$ on day $t$, and $\mathbf{X}_{\mathrm{ct}}$ is a set of county-specific time-varying controls, including whether the county had issued an emergency declaration, whether a non-essential business closure order had been enacted (but not a SIPO), the average temperature in the county, and whether measurable precipitation fell in the county. In addition, $\alpha_{\mathrm{c}}$ is a county fixed effect and $\tau_{\mathrm{t}}$ is a day fixed effect. This model, and all models that follow, are weighted using the county population and utilize standard errors corrected for clustering at the county-level (Bertrand et al. 2004).

We next explore whether the social distancing effects of SIPOs differ by whether the county was more highly urbanized or more densely populated:

$$
\text { PCTHOME } E_{\mathrm{ct}}=\gamma_{0}+\gamma_{1} \text {SIPO }_{\mathrm{ct}} * \boldsymbol{U r b a n}_{\mathrm{c}}+\mathbf{X}_{\mathrm{ct}} \boldsymbol{\beta}_{2}+\alpha_{\mathrm{c}}+\tau_{\mathrm{t}}+\varepsilon_{\mathrm{ct}}
$$

where $\boldsymbol{U r b a n}_{\mathbf{c}}$ identifies mutually exclusive indicators for whether the county urbanicity rate was greater or less than 75 percent in the 2010 Census. Alternatively, we replace $U_{r b a n}$ with PopDensityc, an indicator for whether the county population density was greater than 150 persons per square mile in the 2010 Census. In Texas, 23.6 percent of all counties have urbanicity rates of greater than 75 percent and 13.0 percent are classified as higher population density using our definition. 
Next, we examine the public health effects of local SIPO adoption by focusing on the growth in COVID-19 cases, following Courtemanche et al. (2020a, b), and estimating the following specification that accounts for (i) early SIPO adoption by counties, and (ii) lagged effects of SIPOs:

$$
\begin{aligned}
\text { COVID Growth }_{\mathrm{ct}, \mathrm{t}-1}=\boldsymbol{\beta}_{0} & +\left(\text { SIPO } 0 \text { to } 4 \text { Days }_{\mathrm{ct}} * \text { Adopt }_{c}\right) \boldsymbol{\beta}_{\mathbf{1}} \\
& +\left(\text { SIPO } 5 \text { to } 8 \text { Days }_{\mathrm{ct}} * \text { Adopt }_{c}\right) \boldsymbol{\beta}_{\mathbf{2}} \\
& +\left(\text { SIPO } 9 \text { to } 18 \text { Days }_{\mathrm{ct}} * \text { Adopt }_{c}\right) \boldsymbol{\beta}_{\mathbf{3}} \\
& +\left(\text { SIPO }>18 \text { Days }_{\mathrm{ct}} * \text { Adopt }_{c}\right) \boldsymbol{\beta}_{\mathbf{4}} \\
& +\mathbf{X}_{\mathrm{c}}{ }_{\mathrm{c}} \boldsymbol{\beta}_{5}+\alpha_{\mathrm{c}}+\tau_{\mathrm{t}}+\varepsilon_{\mathrm{ct}}
\end{aligned}
$$

where COVID Growth $h_{\mathrm{ct}, \mathrm{t}-1}$ is the difference in the natural log of cumulative COVID-19 cases in county $c$ on day $t$ and day $t-1$, and thus reflects new confirmed cases each day. SIPO Days denotes lagged effects of SIPOs that correspond to (i) the incubation period of COVID-19 (Lauer et al. 2020), ${ }^{10}$ (ii) post-treatment windows where early adopting counties have enacted a SIPO prior to the statewide order on April 2, and (iii) longer-run post-treatment periods when prior studies have detected larger health effects of SIPOs (Courtemanche et al. 2020; Friedson et al. 2020; Dave et al. 2020). Adopt $\boldsymbol{c}_{c}$ is a mutually exclusive set of indicators for whether a Texas county adopted a SIPO prior to March 27, 2020 (“early adopter”), between March 27 and April 1, 2020 ("later county adopter”), or a non-adopting county bound by the statewide Texas SIPO enacted on April 2, 2020 ("non-adopter"). Additional controls are the same as above.

Identification of our key parameters of interest, $\gamma_{1}$ (equations 1 and 2) and $\beta_{1}$ through $\beta_{4}$ (equation 3) comes from within-county variation in SIPO adoption. Over the sample period

\footnotetext{
${ }^{10}$ The incubation period for COVID-19 is 2 to 14 days, with the median incubation period being 5 days.
} 
under study, a total of 85 counties (or cities larger than 100,000 in those counties) adopted local SIPOs. Thirty-four (34) of these counties adopted their orders between March 24, 2020 and March 26, 2020, and an additional 51 counties did so between March 27 and April 1. A total of 169 counties were newly bound by the statewide SIPO enacted on April 2. Figure 1 shows the geographic dispersion of these counties, reflecting that many of Texas's most densely populated and highly urbanized counties (e.g. Bexar County, Dallas County, Harris County, Tarrant County, Travis County, and El Peso County) adopted SIPOs prior to March 27, allowing for at least a week lag before the state’s adoption of a statewide SIPO on April 2.

In order to produce unbiased estimates of the effect of SIPOs on COVID-19-related health, the parallel trends assumption must be satisfied. This assumption would be visibly violated if (i) SIPOs were adopted in response to changes in COVID-19 case growth, or (ii) SIPOs serve as an observable marker for difficult-to-measure county-specific variables that are correlated with coronavirus growth, such as local information shocks or voluntary social distancing. We extend the baseline difference-in-differences specification to address these concerns. First, we augment equation (3) with controls for county-specific time trends to partial out unmeasured county characteristics trending over time:

$$
\begin{aligned}
& \text { COVID Growth } \text { ct, } \mathrm{t}-1=\beta_{0}+\left(\text { SIPO } 0 \text { to } 4 \text { Days }_{\mathrm{ct}} * \text { Adopt }_{\mathrm{c}}\right) \boldsymbol{\beta 1} \\
& \text { + (SIPO } \left.5 \text { to } 8 \text { Days }_{\mathrm{ct}} * \text { Adopt }_{c}\right) \boldsymbol{\beta 2} \\
& \text { + (SIPO } \left.9 \text { to } 18 \text { Days }_{\mathrm{ct}} * \text { Adopt }_{c}\right) \boldsymbol{\beta} 3 \\
& +\left(\text { SIPO }>18 \text { Days }_{\mathrm{ct}} * \text { Adopt }_{c}\right) \boldsymbol{\beta 4} \\
& +\mathbf{X}^{\prime}{ }_{\mathrm{ct}} \boldsymbol{\beta}_{5}+\alpha_{\mathrm{c}}+\tau_{\mathrm{t}}+\alpha_{\mathrm{c}}{ }^{*} \text { time }+\alpha_{\mathrm{c}}{ }^{*} \text { time }{ }^{2}+\varepsilon_{\mathrm{ct}}
\end{aligned}
$$

where $\left(\alpha_{c}{ }^{*}\right.$ time $+\alpha_{c}{ }^{*}$ time $\left.{ }^{2}\right)$ constitutes county-specific linear and quadratic time trends. We also experiment with linear and county-specific third-order polynomial time trends with a very 
similar pattern of results. Notably, the trends help to account for unobserved factors driving the exponential growth trajectory of COVID-19 transmissions, and effects in these models are identified off deviations from this trend growth. These controls may also be important in controlling for heterogeneity across counties in the timing of coronavirus outbreak as well as for heterogeneity in growth of COVID-19 testing, a point to which we return below.

In addition, we also conduct event study analyses where we allow the difference-indifferences estimate of a SIPO on COVID-19 case growth to differ in the periods prior to and after adoption. Specifically, we examine the effect of county SIPO adoption in the period from 12 or more days prior to adoption through more than 18 days following adoption. This allows us to test for parallel pre-treatment trends to ensure that our policy estimates are not contaminated by COVID-related health trends prior to adoption. ${ }^{11}$

Finally, we explore whether COVID-19 growth rates differ by urbanicity or population density. There is evidence that state SIPOs may be more effective in more highly urbanized or densely populated states (Dave et al. 2020). However, it has not been established whether such a relationship exists within-states with local SIPOs or whether later statewide SIPOs are necessary in such circumstances. This directly gets at the question of if early-adopted urban SIPOs can largely protect the state from an outbreak. To that end, we estimate:

$$
\begin{aligned}
& \text { COVID Growth }_{\mathrm{ct}, \mathrm{t}-1}=\beta_{0}+\left(\text { SIPO } 0 \text { to } 4 \text { Days }_{\mathrm{ct}} * \text { Adopt }_{\boldsymbol{c}} * \text { Urban }_{c}\right) \boldsymbol{\beta}_{1} \\
& +\left(\text { SIPO } 5 \text { to } 8 \text { Days }_{\mathrm{ct}} * \text { Adopt }_{\mathrm{c}} * \text { Urban }_{c}\right) \boldsymbol{\beta}_{2} \\
& +\left(\text { SIPO } 9 \text { to } 18 \text { Days }_{\mathrm{ct}} * \text { Adopt }_{c} * \text { Urban }_{c}\right) \boldsymbol{\beta}_{3} \\
& +\left(\text { SIPO }>18 \text { Days }_{\mathrm{ct}} * \text { Adopt }_{\mathbf{c}} * \text { Urban }_{c}\right) \boldsymbol{\beta}_{\mathbf{4}} \\
& +\mathbf{X}^{\prime}{ }_{\mathrm{ct}} \boldsymbol{\beta}_{5}++\alpha_{\mathrm{c}}+\tau_{\mathrm{t}}+\alpha_{\mathrm{c}}{ }^{*} \text { time }+\alpha_{\mathrm{c}}{ }^{*} \text { time }^{2}+\varepsilon_{\mathrm{ct}}
\end{aligned}
$$

\footnotetext{
${ }^{11}$ Event studies have the additional value of generating unbiased estimates in the case of multiple policy interventions with differential timing (Sun and Abraham 2020), helping to alleviate concerns of bias in the difference in differences analysis (Goodman-Bacon 2018).
} 
In alternate specifications, we replace Urban ${ }_{\mathrm{c}}$ with PopDensityc. This approach allows us to test whether early adopting urbanized counties and more densely populated counties drove larger reductions in case growth.

\section{Results}

Tables 1 through 3 and Figure 2 show the main findings from our study. Our tables only report the coefficients on the SIPO variables. Estimates on the control variables are available in Online Appendix Table 2.

Panel I of Table 1 shows findings from equation (1) using SafeGraph data on social distancing. In the first column, we present results for the most parsimonious specification, controlling for only county and day fixed effects. We find that the enactment of a county SIPO is associated with a statistically significant 2.4 percentage-point increase in the probability of staying at home full-time. In columns 2 through 4, we assess whether this estimated policy response is robust to controlling for county-specific trends, additional COVID-19 related policy controls (i.e. non-essential business closures and emergency declarations), and temperature and precipitation controls. The results are largely unchanged, suggesting an increase of 2.9 to 3.0 percentage-point increase, which translates into a 13 to 14 percent increase relative to the mean stay-at-home rate for Texas at the start of our sample period.

Panel (a) of Figure 2 visually presents the dynamics in stay-at-home behavior from an event study analysis, highlighting three main points. ${ }^{12}$ First, the lead pre-policy effects are close to zero indicating that trends in social distancing between the SIPO-adopting and non-adopting

\footnotetext{
${ }^{12}$ See Appendix Figure 2 for event study graphs based on alternate groupings of leads and lags, and the fullyflexible non-grouped leads and lags by each day.
} 
counties were parallel prior to enactment. Second, the marked increase in sheltering-at-home in the treated counties relative to the non-adopters materializes only after the implementation of the SIPO. Finally, the increase in social distancing within the treated counties remains sustained through the observed post-treatment window. These localized results are in line with previous state-level findings (Friedson et al. 2020; Dave et al. 2020), and confirm that shelter-at-home orders proclaimed by local jurisdictions improved compliance with social distancing.

Given that social distancing inherently involves a decrease in person-to-person contact for economic or non-economic reasons, we explore how these social distancing effects of localized SIPOs vary depending on the county's urbanicity and population density, both of which are independent predictors of social interactions. Models reported in Panels II and III, based on equation (2), consistently show that, while the orders were effective across the board in encouraging individuals to shelter at home, the effects are significantly larger in urbanized and more densely populated counties (3.4 percentage points vs. 1.6 to 1.7 percentage points in less urban and sparsely populated counties).

Given this evidence that the local SIPOs were successful in inducing county residents to stay at home, we then assess the public health effects of the local SIPO adoption, focusing on county-level heterogeneity in the timing of the adoption, based on equation (3). These results are presented in Table 2. The first column reports results from the most parsimonious specification as a baseline for comparison. Here we find significant reductions in the COVID-19 case growth following implementation of a local SIPO, but only for the earliest adopting counties. Growth in cases fell by 13.5 percentage points within 4 days of implementation, and by 15.3 percentage points within 8 days of implementation, a window of time that includes the $75^{\text {th }}$ percentile of the virus's incubation period and, importantly, which also largely precedes the implementation of the 
statewide SIPO. The effects accelerate as the post-policy window widens in length, with the growth in COVID-19 cases declining on average by 19.4 percentage points following 18 days after SIPO adoption. For later adopting counties, there are some suggestive declines in case growth, though these are much smaller in magnitude and not statistically significant at conventional levels.

In column (2), we add controls for county-specific linear and quadratic trends, based on equation (4), to address the spatial heterogeneity within the state in the growth track of confirmed cases (Appendix Figure 1). These controls serve an important purpose in accounting for the exponential growth path of the outbreak prior to reaching its peak. For these models the estimated SIPO effects are identified off deviations from each county's growth path. As with the results in column (1), the strongest reductions post-SIPO in the COVID-19 case growth rate accrue to the earliest adopting counties, with benefits progressively increasing over time. After 18 days post-enactment, average daily growth in cases is 25.2 percent lower in these counties relative to the later and non-adopting counties. With the addition of the trend controls, significant decreases in case growth for the later-adopting counties also emerge, following their local SIPOs, though the declines take a bit longer to materialize (after 5 to 8 days post-enactment) and are somewhat smaller relative to the gains for the early-movers. We continue to find no beneficial effects of the statewide-SIPO for the remaining counties that had not enacted local orders.

The pattern and magnitudes remain largely unchanged after including additional COVID19 related policies and weather controls (columns 3 and 4, respectively). ${ }^{13}$ Panel (b) of Figure 2 presents the event study analysis for the early-adopting counties. Differential pre-treatment

\footnotetext{
${ }^{13}$ We independently control for emergency declarations and non-essential business closure orders, which can precede the adoption of a SIPO.
} 
trends are flat, and there is a sharp and progressively larger decline in the average growth rates in cases ensuing the adoption of the policy.

One potential concern with these estimates is that they may be confounded by differential testing capabilities if access to testing is correlated with the timing of the localized SIPO adoption. ${ }^{14}$ Baseline differences in testing rates would be captured by the county fixed effects, and the county linear trends go a long way towards addressing time-varying localized differences in testing capacity, though not fully. To account for any residual systematic variation in testing capacity, we draw on cumulative testing data obtained from the Texas Department of State Health Services. In column (5), we restrict our analysis to only those counties that had achieved a relatively high cumulative testing rate, at or above the state median. ${ }^{15}$ This ensures a more homogeneous set of localities with respect to testing availability. In spite of the large sample restriction, the results remain remarkably robust, with no evidence that our estimates are driven by local differences in testing.

Not all localities experienced the coronavirus outbreak the same time. To ensure comparability in the start of the outbreak cycle across counties, column (6) restricts the sample such that a county enters the analysis only after it has experienced the start of the outbreak and some level of community spread (at least two cases). ${ }^{16}$ The final column accounts for any potential border spillovers by controlling for the share of population in bordering counties that

\footnotetext{
${ }^{14}$ In the presence of testing shortages, wherein tests are allocated to relatively sicker patients, confirmed counts of COVID-19 cases are more likely to reflect severe cases, which is arguably a more salient indicator of infections for studying the public health effects of a SIPO (Courtemanche et al. 2020a).

${ }^{15}$ The earliest date that these data are available at the county level in a consistent format is April 8, which is when we calculate the median testing rate. The median cumulative testing rate across TX counties was 10.7 (per 10,000 residents) as of April 8, and statewide mean was 24.9. Restricting the sample to counties with a cumulative testing rate at the $60^{\text {th }}$ (testing rate $>14.6$ ) or at the $75^{\text {th }}$ percentile (testing rate $>19.3$ ), or counties with a testing rate that exceeded the state mean ( $>24.9$ ) yields similar results and conclusions.

${ }^{16}$ We also tested alternate thresholds, based on counties experiencing at least $1,3,4$, and 5 confirmed cases, with estimates remaining largely unchanged.
} 
are covered by a SIPO. ${ }^{17}$ Both sets of results continue to support the effectiveness of local SIPOs among counties that adopted these orders well in advance of the statewide order.

The findings from Table 2 can be summarized as follows. Counties that implemented their own local SIPOs, prior to the statewide order, experienced significant declines in the daily case growth, with the strongest benefits accruing to the earliest adopters. Furthermore, the decline in case growth accelerated over the post-policy window, with the growth rate reduced by up to 26.2 percentage points for the early adopters and up to 21.1 percentage points for the later adopting counties, from greater than 18 days following enactment.

In light of our earlier evidence that the effectiveness of local SIPOs is at least partly propelled by an increase in social distancing, with stronger responses realized in urbanized and highly populated localities, next we explore whether the public health effects also line up with this spatial heterogeneity in the social distancing effects. Urbanicity and population density play a key role in the propagation of infectious diseases across communities. Hence, these factors can serve as multipliers that can enhance the efficacy of a given level of social distancing. In light of this, the realized gains in public health from the SIPOs may be larger in urban and more populated communities because of a larger social distancing effect induced by the SIPO (as shown in Table 1) and also because of a larger marginal benefit of given level of social distancing in more urban and populated localities.

Table 3 presents estimates of heterogeneous responses with respect to urbanicity and population density, based on the fully-interacted formulation specified in equation (5). The results show compelling evidence that virtually all of the decline in case growth accrued to urbanized counties and highly populated counties that had adopted a localized shelter-in-place

\footnotetext{
${ }^{17}$ Results are not sensitive to alternately controlling for whether any border county is covered by a local SIPO (including SIPOs in neighboring states for those Texas counties that border other states).
} 
order in advance of the statewide order. After 18 days following enactment, these counties experienced significant declines in the daily growth rate of COVID-19 cases on the order of 26 to 27 percentage points. Evidence from the event study analyses for these sets of early adopting urban and populous counties, shown in panels (c) and (d) of Figure 2, is consistent with common pre-policy trends and a significant post-policy break in the trend. In contrast, less urban and more sparsely populated counties did not reap any significant benefits from their local orders, even if they enacted these orders well ahead of the statewide SIPO. The results in Table 3 continue to indicate that the statewide SIPO did not have any significant impact in flattening the growth trajectory for the remaining non-adopting counties, regardless of their level of urbanization or population density.

In a difference-in-differences estimator with the policy turning on at different times, as with the differential timing of the SIPO adoption across the Texas counties, the treatment effect is a weighted average of the many "mini” experiments comparing: (1) earlier-adopting counties with later-adopters as controls; and (2) non-adopting counties (bound later by the statewide order) with the earlier adopting counties as controls (Goodman-Bacon 2018). Hence, the effects of the statewide SIPO for the non-adopting counties is necessarily identified by comparing their conditional trends pre- and post-SIPO to those of the early adopters. This can be problematic. In the presence of dynamic treatment effects, the early-adopters may not be a good counterfactual for the non-adopters bound by the state order. As the trajectory of the early-adopting counties, at the time when the statewide SIPO extends to the holdout counties, is still being affected by the policy (that is, by the local SIPOs in the early moving counties), the estimated SIPO effects for the non-adopting counties covered by the state order may be biased towards zero. 
In order to assess this potential bias, and more cleanly identify the statewide SIPO effects for the non-adopters, we draw on Goodman-Bacon (2018) and add county-level information from other states that never adopted a statewide SIPO. By introducing another set of counterfactuals - non-adopting counties in other states that were never bound by a statewide order - we are able to derive plausibly consistent policy effects of the statewide SIPO in Texas for the remaining non-adopting counties. Appendix Table 3 presents these results, using all nonadopting states and alternately all bordering non-adopting states, as control groups. The estimates and pattern of results remain robust. We continue to find that the declines in case growth were driven primarily by the early-adopting urbanized and populated counties. There was little to no benefit from issuing a statewide SIPO later, once these localized orders had started to take effect.

\section{Conclusions}

By examining the staggered county implementations of SIPOs in Texas this study has established two important results. First, when urbanized localities mobilize early with shelter-inplace orders, the accrual of public health benefits are substantial. Second, in the presence of early urban SIPO adopters, there may be little gains from a later blanket statewide order. These findings are not surprising given the potential for exponential growth with the spread of disease. Breaking the trend in cases, by acting earlier in areas where spread may be faster, has compounding effects that can greatly alter the trajectory of an outbreak.

As a result, we find in Texas that almost all of the public health benefits from SIPO implementation came from these urban, densely populated areas. ${ }^{18}$ Our estimates indicate that

\footnotetext{
${ }^{18}$ In supplemental analyses, available in Appendix Table 4, we explore other later-adopting SIPO states with more limited early county SIPO adoption relative to the State of Texas. It is validating that results from these miniexperiments in these states produced a pattern of results largely similar to Texas, suggesting that our findings are generalizable.
} 
91.5 percent of the reduction in the growth in COVID-19 cases came just from the early localized adoption of SIPOs in urbanized counties alone. ${ }^{19}$ There is very little gained from a statewide order after this point.

These findings have large implications for the policy landscape going forward. In particular, if the benefits of SIPOs are concentrated in urban areas, then the use of these restrictive policies statewide may not be necessary when fighting outbreaks. More nuanced policy strategies that are stricter in dense urban areas and looser in less dense rural areas may yield similar health benefits without imposing the costs, both in terms of economic activity and in terms of inconvenience on part of the population.

${ }^{19}$ Much of the leftover gains accrues from the later adopting urbanized counties, who are doing so still in advance of the statewide SIPO. See Appendix Table 5 for a discussion of this calculation. 


\section{References}

Allday, Erin. 2020. “Bay Area Orders 'Shelter in Place,' Only Essential Businesses Open in 6 Counties.” San Francisco Chronicle, March 16. Available at: https://www.sfchronicle.com/local-politics/article/Bay-Area-must-shelter-in-place-Only15135014.php

Baek, ChaeWon, Peter B. McCrory, Todd Messer, and Preston Mui. 2020. "Unemployment Effects of Stay-at-Home Orders: Evidence from High Frequency Claims Data.” Institute for Research on Labor and Employment Working Paper No. 101-20.

Bai, Yan, Lingsheng Yao, Tao Wei, Fei Tian, Dong-Yan Jin, Lijuan Chen, and Meiyun Wang. 2020. "Presumed asymptomatic carrier transmission of COVID-19." JAMA, 323(14): 1406-1407.

Bertrand, Marianne, Esther Duflo, and Sendhil Mullainathan. 2004. "How much should we trust differences-in-differences estimates?” The Quarterly Journal of Economics, 119(1): 249275.

Centers for Disease Control. 2020. “COVID-19 How to Protect Yourself and Others.” Available online: https://www.cdc.gov/coronavirus/2019-ncov/prevent-getting-sick/prevention.html

Courtemanche, Charles, Joseph Garuccio, Anh Le, Joshua C. Pinkston, and Aaron Yelowitz. 2020a. "Strong Social Distancing Measures In The United States Reduced The COVID19 Growth Rate.” Health Affairs, in press.

Courtemanche, Charles J., Joseph Garuccio, Anh Le, Joshua C. Pinkston, and Aaron Yelowitz. 2020b. "Did Social-Distancing Measures in Kentucky Help to Flatten the COVID-19 Curve?" Institute for the Study of Free Enterprise Working Paper 2020-4.

Dave, Dhaval M., Andrew I. Friedson, Kyutaro Matsuzawa, and Joseph J. Sabia. 2020. "When Do Shelter-In-Place Orders Fight COVID-19 Best? Policy Heterogeneity across States and Adoption Time.” National Bureau of Economic Research Working Paper No. 27091.

Defense Casualty Analysis System. 2008. "Vietnam War U.S. Military Fatal Casualty Statistics.” Available online: https://www.archives.gov/research/military/vietnam-war/casualty$\underline{\text { statistics }}$

Friedson, Andrew I., Drew McNichols, Joseph J. Sabia, and Dhaval Dave. 2020. "Did California’s Shelter-in-Place Order Work? Early Coronavirus-Related Public Health Effects.” National Bureau of Economic Research Working Paper No. 26992.

Goodman-Bacon, Andrew. 2018. "Difference-in-Differences with Variation in Treatment Timing.” National Bureau of Economic Research Working Paper No. 25108.

Holshue, Michelle L., Chas DeBolt, Scott Lindquist, Kathy H. Lofy, John Wiesman, Hollianne Bruce, Christopher Spitters, et al. 2020. "First case of 2019 novel coronavirus in the United States.” New England Journal of Medicine, 382: 929-936.

Johns Hopkins University. 2020. “COVID-19 Case Tracker.” Available online: https://coronavirus.jhu.edu/map.html

Lauer, Stephen A., Kyra H. Grantz, Qifang Bi, Forrest K. Jones, Qulu Zheng, Hannah R. Meredith, Andrew S. Azman, Nicholas G. Reich, and Justin Lessler. 2020. "The Incubation Period of Coronavirus Disease 2019 (COVID-19) from Publicly Reported Confirmed Cases: Estimation and Application.” Annals of Internal Medicine 
Mervosh, Sarah, Denise Lu, and Vanessa Swales. "See Which States and Cities Have Told Residents to Stay at Home.” The New York Times, April 7. Available at:

https://www.nytimes.com/interactive/2020/us/coronavirus-stay-at-home-order.html

National Association of Counties. 2020. "County Declarations and Policies In Response to COVID-19 Pandemic.” Available at: https://ce.naco.org/?dset=COVID19\&ind=Emergency\%20Declaration\%20Types

Pan, Xingfei, Dexiong Chen, Yong Xia, Xinwei Wu, Tangsheng Li, Xueting Ou, Liyang Zhou, and Jing Liu. 2020. "Asymptomatic cases in a family cluster with SARS-CoV-2 infection.” The Lancet Infectious Diseases, 20(4): 410-411.

Rothe C, Schunk M, Sothmann P, et al. 2020. "Transmission of 2019-nCoV Infection from an Asymptomatic Contact in Germany.” New England Journal of Medicine, 382:970-971.

Sun, Liyang, and Sarah Abraham. 2020. "Estimating Dynamic Treatment Effects in Event Studies with Heterogeneous Treatment Effects” Working Paper.

Wilson, Steven G., David A. Plane, Paul J. Mackun, Thomas R. Fischetti, and Justyna Goworowska. 2020. "Patterns of Metropolitan and Micropolitan Population Change 2000 to 2020.” 2010 Census Special Reports. U.S. Census Bureau. Report C2020SR-01. 
Figure 1: Enactment of County Shelter-in-Place Orders in Texas

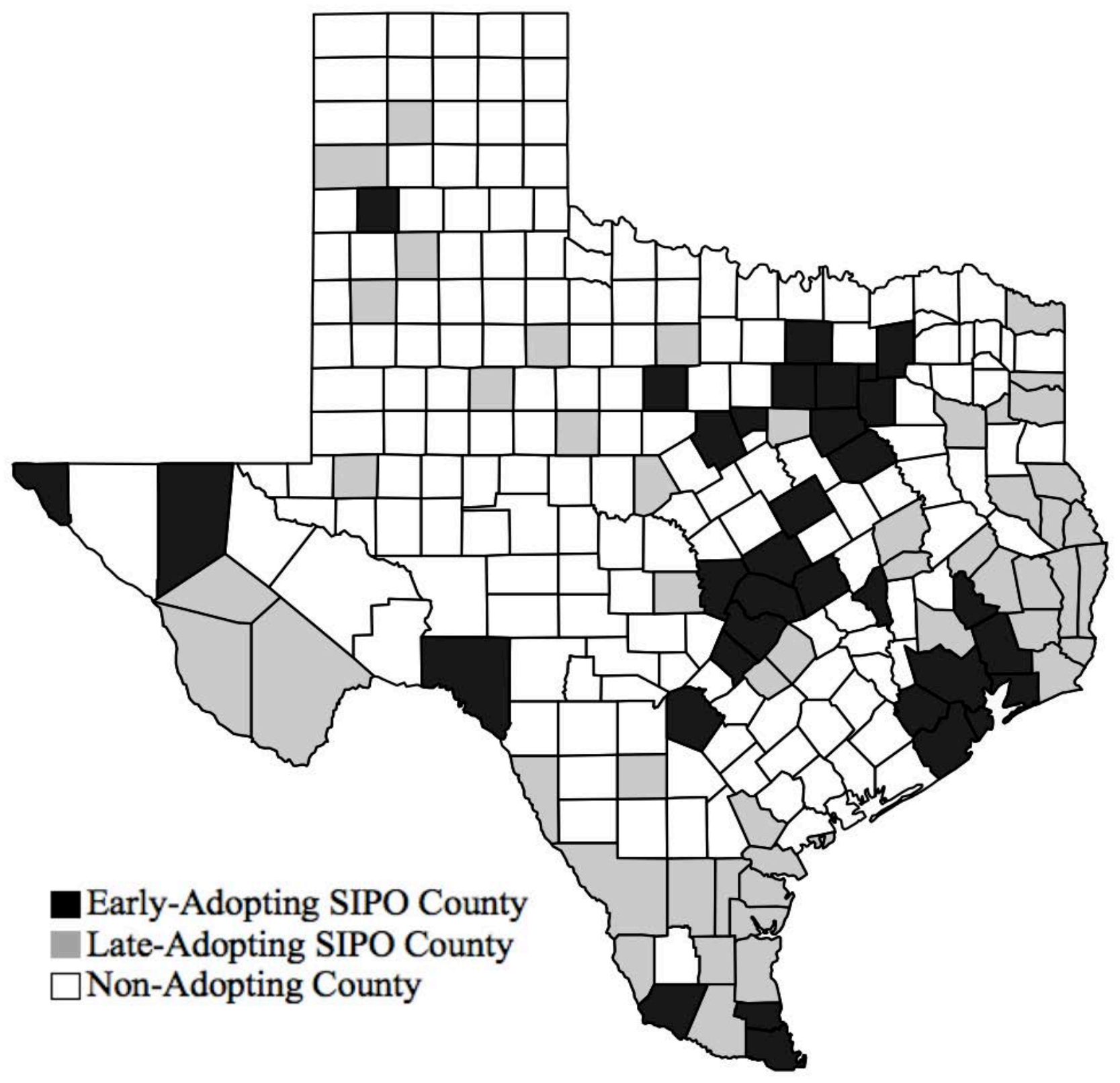

Notes: Counties that adopted SIPO on March 26 or before are defined as Early-Adopting SIPO Counties; counties that adopted SIPO between March 27 and April 1 are defined as Late-Adopting SIPO Counties; and counties that never adopted a SIPO (but were bound by the statewide order) are defined as Non-Adopting Counties. 
Figure 2: Event Study Analyses of Effects of Shelter-In-Place Orders on Social Distancing and COVID-19 Case Growth

Panel (a): Percent Staying at Home Full-Time

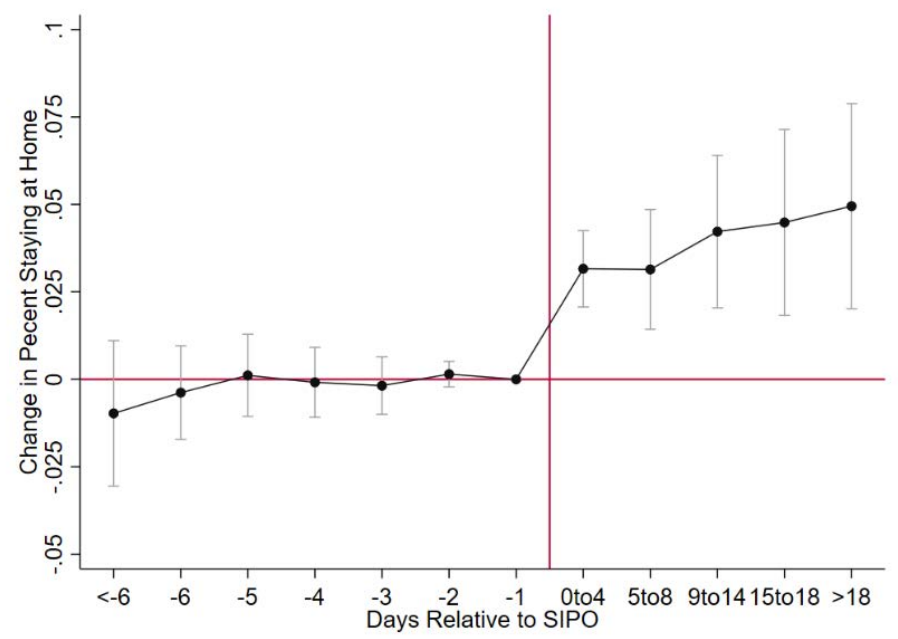

Panel (c): COVID-19 Growth for Urban Early SIPO Counties

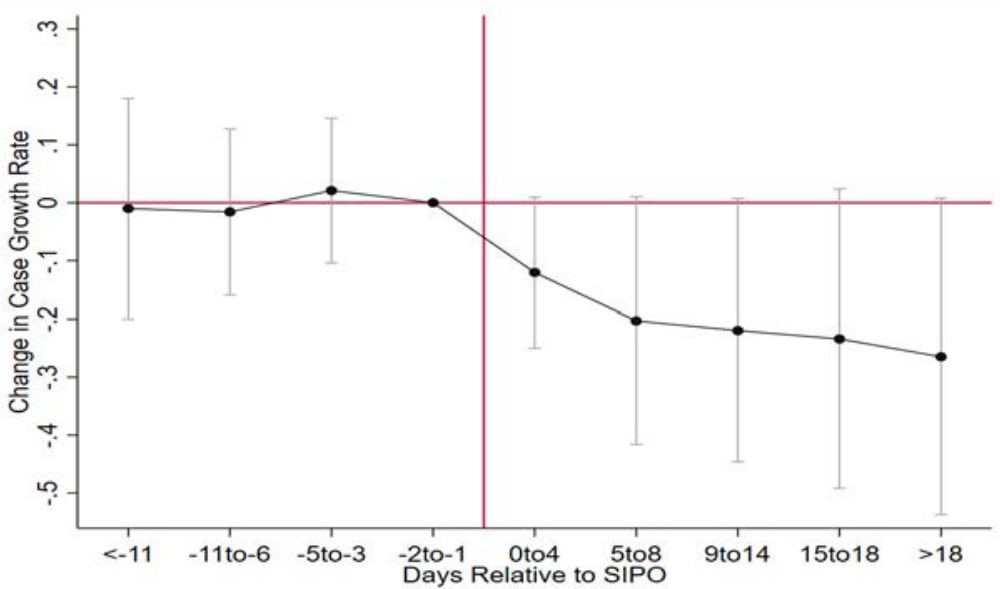

Panel (b): COVID-19 Growth for Early-Adopting SIPO Counties

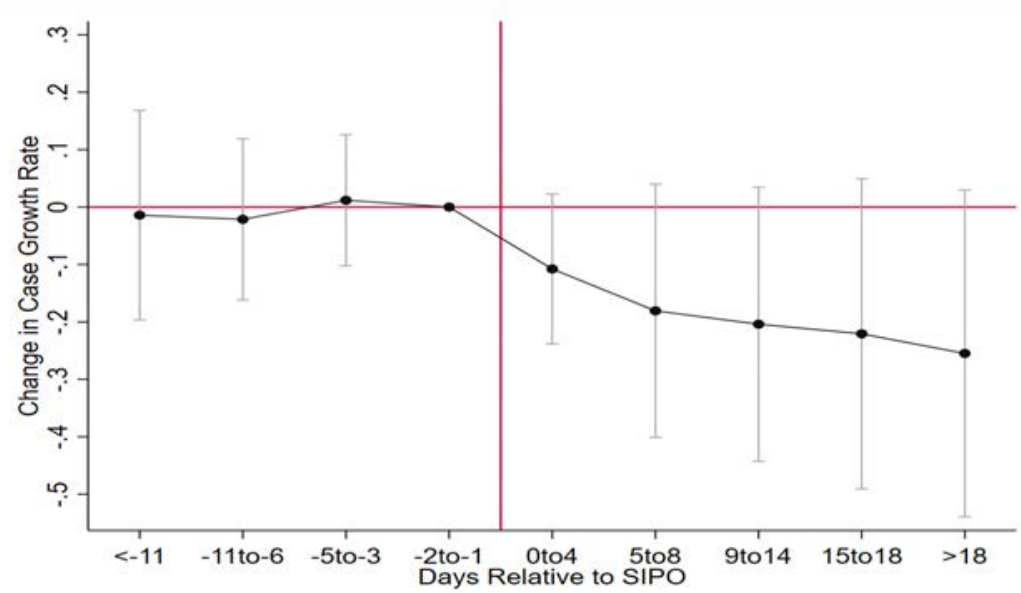

Panel (d): COVID-19 Growth for High Population Density Early SIPO Counties

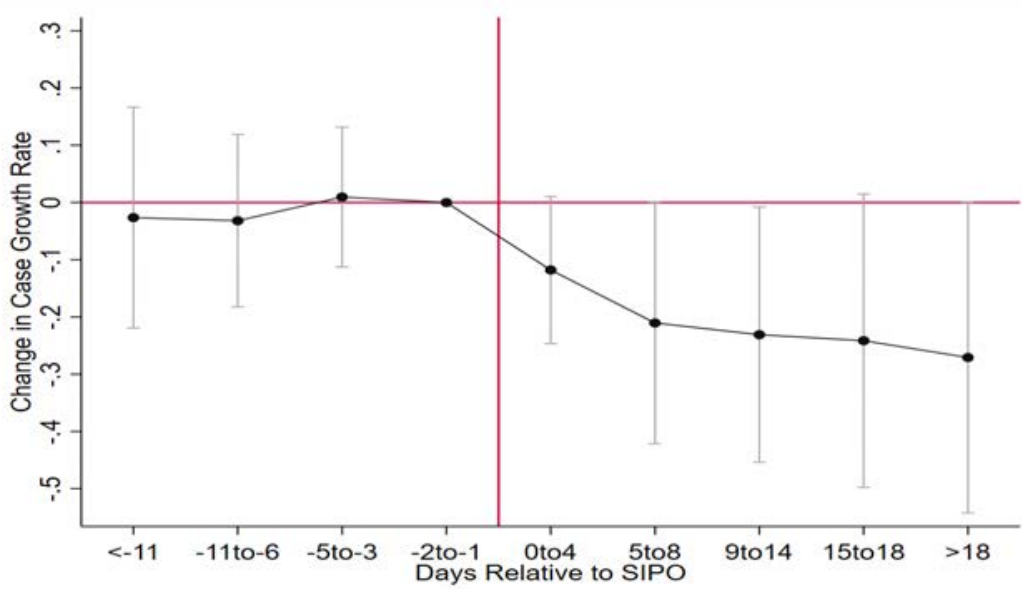

Notes: Estimates are obtained using weighted least squares regression. The model includes the following controls: an indicator for whether thecounty had issued a non-essential business closure order, an indicator for whether the county had issued an emergency declaration, the average temperature (in degrees Celsius) in the county, an indicator for whether measurable precipitation fell in the county, county fixed effects, day fixed effects, and a county-specific quadratic time trend. Standard errors are clustered at the county-level. 


\section{Table 1: Difference-in-Differences Estimates of Effect of Shelter-in-Place Orders on Percent Staying at Home Full-Time}

(1)

(2)

(3)

(4)

Panel I: Difference-in-Difference Estimate

SIPO

\begin{tabular}{cccc}
\hline $0.024^{* * *}$ & $0.030^{* * *}$ & $0.030^{* * *}$ & $0.029 * * *$ \\
$(0.005)$ & $(0.006)$ & $(0.006)$ & $(0.006)$
\end{tabular}

Panel II: Heterogeneous Treatment Effect by Urbanicity

SIPO $* \geq 75 \%$ Urbanicity

$\begin{array}{cccc}0.033^{* * *} & 0.034^{* * *} & 0.034^{* * *} & 0.034^{* * *} \\ (0.006) & (0.007) & (0.008) & (0.008) \\ 0.007 & 0.016^{* * *} & 0.016^{* * *} & 0.016^{* * *} \\ (0.005) & (0.005) & (0.005) & (0.005)\end{array}$

Panel III: Heterogeneous Treatment Effect by Population Density

SIPO * $\geq 150$ People Per Sq. Mi

$0.033^{* * *}$

$0.034 * * *$

$0.034 * * *$

$0.034 * * *$

SIPO * < 150 People Per Sq. Mi

(0.007)

(0.007)

0.008

$0.017 * * *$

(0.006)

(0.005)

(0.008)

(0.008)

$0.017 * * *$

(0.005)

(0.005)

12954

Yes

12954

Yes

No

Yes

No

No

No
12954

Yes

Yes

Yes

No
12954

Yes

Yes

Yes

Yes
Weather Controls?

No

Notes: Estimates are obtained using weighted least squares regression. The model includes the following controls: an indicator for whether the county had issued a non-essential business closure order, an indicator for whether the county had issued an emergency declaration, the average temperature (in degrees Celsius) in the county, an indicator for whether measurable precipitation fell in the county, county fixed effects, day fixed effects, and a county-specific quadratic time trend. Standard errors, clustered at the county-level, are reported in parenthesis. 
Table 2: Difference-in-Differences Estimates of Effect of Shelter-in-Place Orders on COVID-19 Case Growth

(1) (2)

(3)

(4)

(5)

(6)

(7)

\section{Early-Adopting SIPO Counties}

0-4 Days After

$\begin{array}{ccccccc}-0.135^{* * *} & -0.158^{* * *} & -0.152^{* * *} & -0.150^{* * *} & -0.171^{* * *} & -0.128^{* *} & -0.118^{* *} \\ (0.043) & (0.042) & (0.044) & (0.043) & (0.048) & (0.052) & (0.055) \\ -0.153^{* * *} & -0.196^{* * *} & -0.186^{* * *} & -0.184^{* * *} & -0.202^{* * *} & -0.166^{* *} & -0.154^{* *} \\ (0.055) & (0.055) & (0.058) & (0.058) & (0.066) & (0.081) & (0.072) \\ -0.164 * * & -0.218^{* * *} & -0.207 * * * & -0.210^{* * *} & -0.220^{* * *} & -0.176^{* *} & -0.181^{* *} \\ (0.068) & (0.068) & (0.072) & (0.072) & (0.080) & (0.084) & (0.083) \\ -0.194 * * * & -0.252^{* * *} & -0.242^{* * *} & -0.251^{* * *} & -0.262^{* * *} & -0.207 * * & -0.222^{* * *} \\ (0.071) & (0.067) & (0.070) & (0.070) & (0.078) & (0.086) & (0.082)\end{array}$

Late-Adopting SIPO Counties

0-4 Days After

0.014

$-0.035$

$-0.031$

$-0.031$

$-0.049$

$-0.069$

$-0.001$

5-8 Days After

(0.050)

(0.051)

(0.049)

(0.049)

(0.057)

(0.059)

(0.059)

$-0.038$

$-0.107 *$

$-0.102 *$

$-0.105^{*}$

$-0.120^{*}$

$-0.125^{* *}$

$-0.072$

9-18 Days After

(0.056)

(0.057)

(0.057)

(0.058)

$-0.054$

$-0.142 * *$

$-0.136^{* *}$

$-0.141^{* *}$

(0.066)

(0.060)

(0.069)

(0.055)

(0.055)

(0.055)

(0.054)

$-0.155^{* *}$

$-0.150 * *$

-0.108 *

>18 Days After

$-0.078$

$-0.197 * * *$

$-0.191 * * *$

(0.062)

(0.061)

(0.065)

(0.059)

(0.061)

(0.061)

0.197 ***

$-0.211 * * *$

$-0.181^{* * *}$

$-0.162 * *$

Non-Adopting Counties Bound by State SIPO

0-4 Days After

$-0.054$

(0.033)

5-8 Days After

$-0.033$

(0.036)

9-18 Days After

>18 Days After

$-0.053$

(0.040)

$-0.049$

(0.041)

$\mathrm{N}$

County \& Day Fixed Effects?

County Time Trend?

NEBCO \& Emergency Declaration?

Weather Controls?

Testing Rate $\geq$ Median?

Sample w/ Cases $\geq 2$

Weighted Population Share of

Border Counties w/ SIPO

12954

Yes

No

No

No

No

No

$\begin{array}{cccccc}-0.031 & -0.026 & -0.030 & -0.039 & -0.074 * & -0.001 \\ (0.040) & (0.044) & (0.044) & (0.049) & (0.043) & (0.053) \\ 0.019 & 0.025 & 0.020 & 0.004 & -0.059 & 0.048 \\ (0.049) & (0.053) & (0.053) & (0.060) & (0.047) & (0.059) \\ 0.055 & 0.063 & 0.051 & 0.049 & -0.053 & 0.077 \\ (0.069) & (0.074) & (0.072) & (0.084) & (0.061) & (0.076) \\ 0.154 & 0.164 & 0.142 & 0.152 & -0.004 & 0.168 \\ (0.105) & (0.109) & (0.105) & (0.127) & (0.086) & (0.105)\end{array}$

12954

Yes

Yes

No

No

No

No

12954

Yes

Yes

Yes

No

No

No

12954

Yes

Yes

Yes

Yes

No

No

\section{7}

Yes

Yes

Yes

Yes

Yes

No

No

No

\section{8}

Yes

Yes

Yes

Yes

No

Yes

No
12954

Yes

Yes

Yes

Yes

No

No

Yes 
Notes: Estimates are obtained using weighted least squares regression. The model includes the following controls: an indicator for whether the county had issued a non-essential business closure order, an indicator for whether the county had issued an emergency declaration, the average temperature (in degrees Celsius) in the county, an indicator for whether measurable precipitation fell in the county, county fixed effects, day fixed effects, and a county-specific quadratic time trend. Standard errors, clustered at the county-level, are reported in parenthesis. Counties that adopted SIPO on March 26 or before are defined as Early-Adopting SIPO Counties, and counties that adopted SIPO between March 27 and April 1 are defined as Late-Adopting SIPO Counties. 
Table 3. Heterogeneity in Effects of Shelter-in-Place Orders on COVID-19 Case Growth, by Urbanicity and Population Density

\begin{tabular}{ll} 
Urbanicity & \\
\hline$\geq 75 \%$ & $<75 \%$
\end{tabular}

(1)
(2)

\begin{tabular}{cc}
\multicolumn{2}{c}{ Population Density } \\
\hline$\geq 150$ persons per & $<150$ persons per \\
sq-mi & sq-mi \\
(3) & $(4)$
\end{tabular}

\section{Early-Adopting SIPO Counties}

\begin{tabular}{lcccc}
\hline 0-4 Days After & $-0.161^{* * *}$ & -0.052 & $-0.162^{* * *}$ & -0.014 \\
& $(0.043)$ & $(0.044)$ & $(0.043)$ & $(0.053)$ \\
5-8 Days After & $-0.200^{* * *}$ & -0.013 & $-0.201^{* * *}$ & -0.004 \\
& $(0.057)$ & $(0.051)$ & $(0.058)$ & $(0.047)$ \\
9-18 Days After & $-0.219^{* * *}$ & -0.060 & $-0.223^{* * *}$ & -0.035 \\
& $(0.070)$ & $(0.060)$ & $(0.072)$ & $(0.061)$ \\
>18 Days After & $-0.259^{* * *}$ & -0.078 & $-0.264^{* * *}$ & -0.061 \\
& $(0.067)$ & $(0.070)$ & $(0.068)$ & $(0.070)$
\end{tabular}

Late-Adopting SIPO Counties

$\begin{array}{lcccc}\text { 0-4 Days After } & -0.040 & -0.009 & -0.047 & -0.003 \\ & (0.057) & (0.048) & (0.060) & (0.049) \\ \text { 5-8 Days After } & -0.132^{* *} & -0.029 & -0.144^{* *} & -0.031 \\ & (0.062) & (0.055) & (0.062) & (0.056) \\ \text { 9-18 Days After } & -0.184^{* * *} & -0.016 & -0.190^{* * *} & -0.032 \\ & (0.055) & (0.055) & (0.056) & (0.068) \\ \text { >18 Days After } & -0.263^{* * *} & -0.010 & -0.268^{* * *} & -0.034 \\ & (0.064) & (0.062) & (0.065) & (0.093)\end{array}$

Non-Adopting Counties Bound by State SIPO

\begin{tabular}{lcccc}
\hline 0-4 Days After & -0.040 & -0.019 & -0.061 & -0.013 \\
& $(0.054)$ & $(0.039)$ & $(0.059)$ & $(0.042)$ \\
5-8 Days After & -0.001 & 0.041 & -0.015 & 0.043 \\
& $(0.077)$ & $(0.047)$ & $(0.082)$ & $(0.052)$ \\
9-18 Days After & 0.075 & 0.040 & 0.073 & 0.044 \\
& $(0.117)$ & $(0.063)$ & $(0.123)$ & $(0.068)$ \\
>18 Days After & 0.203 & 0.107 & 0.222 & 0.108 \\
& $(0.194)$ & $(0.090)$ & $(0.203)$ & $(0.097)$ \\
N & & & & \\
& 12954 & 12954 & 12954 & 12954
\end{tabular}

Notes: Estimates are obtained using weighted least squares regression. The model includes the following controls: an indicator for whether the county had issued a non-essential business closure order, an indicator for whether the county had issued an emergency declaration, the average temperature (in degrees Celsius) in the county, an indicator for whether measurable precipitation fell in the county, county fixed effects, day fixed effects, and a county-specific quadratic time trend. Standard errors, clustered at the county-level, are reported in parenthesis. Counties that adopted SIPO on March 26 or before are defined as EarlyAdopting SIPO Counties, and counties that adopted SIPO between March 27 and April 1 are defined as Late-Adopting SIPO Counties. 


\section{Online Appendix Figures and Tables}


Appendix Figure 1: Trends in Texas COVID-19 Cases

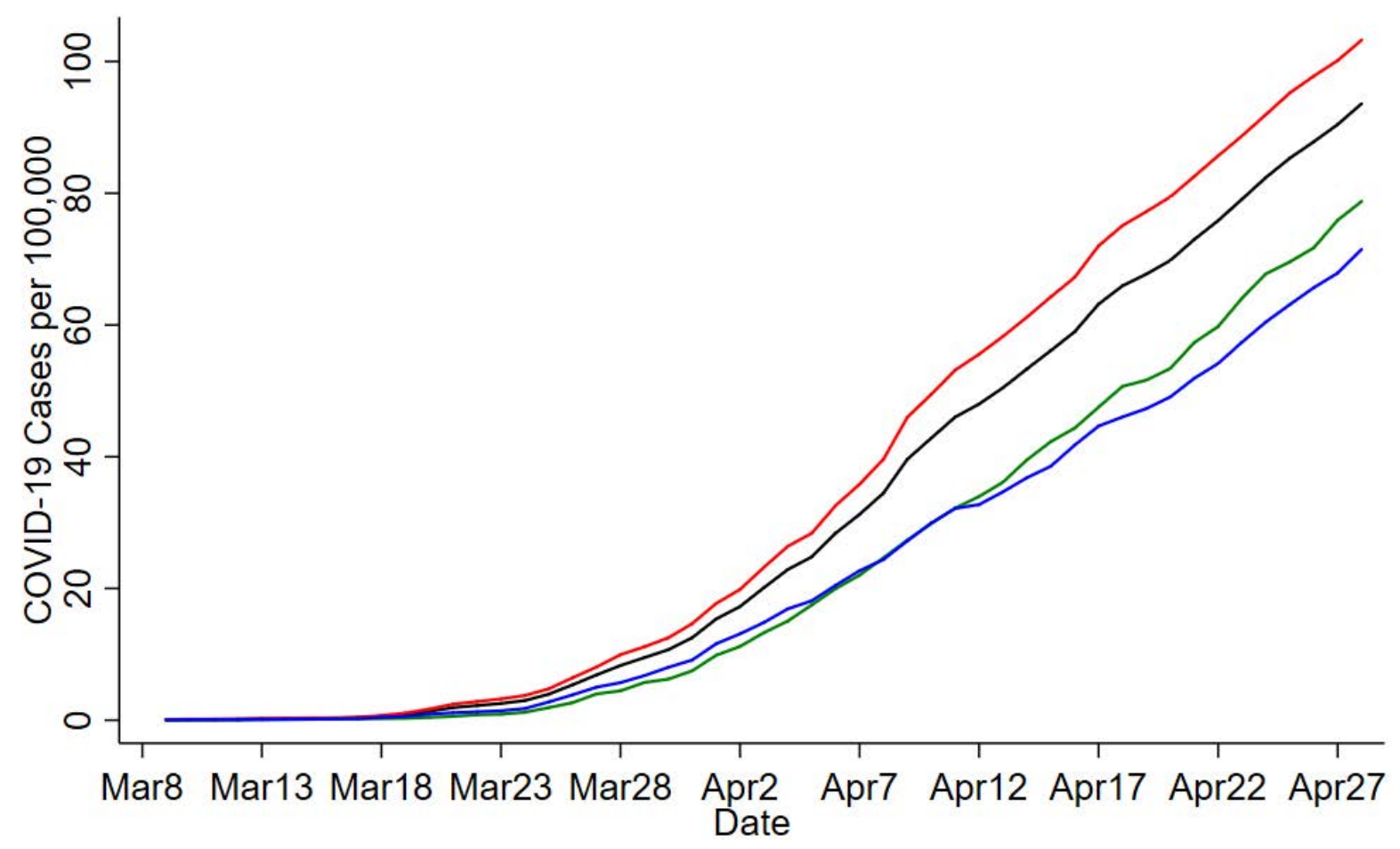

$\begin{array}{ll}- \text { TX Average } & \text { Early Adopting Counties } \\ \text { Later Adopting Counties } & \text { Non-Adopting Counties }\end{array}$


Appendix Figure 2: Event Studies Analysis of Effect of SIPOs on Percent Staying at Home Full-Time

(a) Individual Leads and Lags

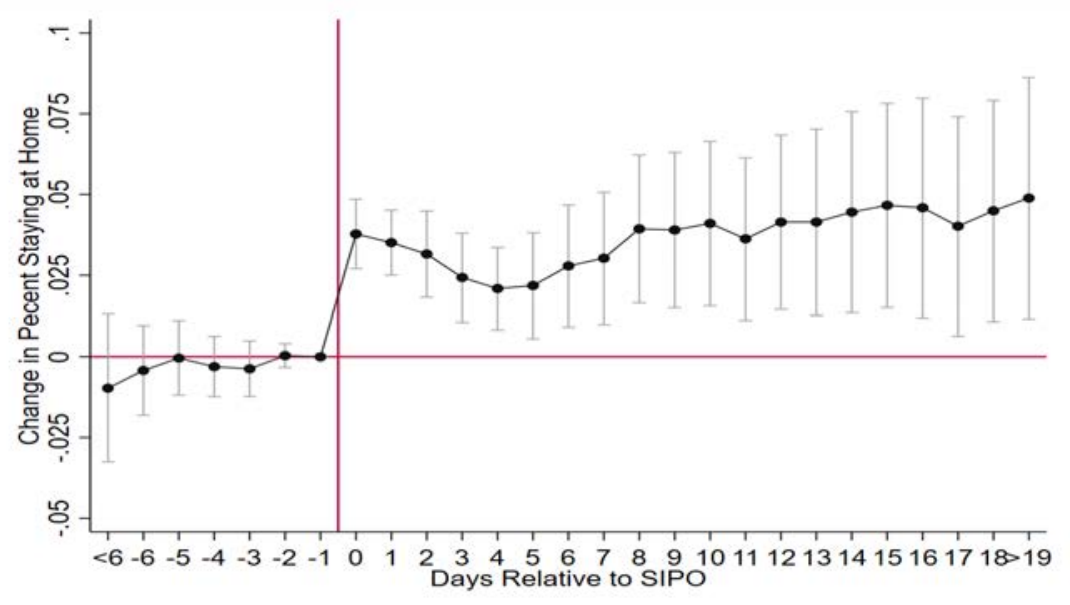

(c) Grouped Leads and Lags

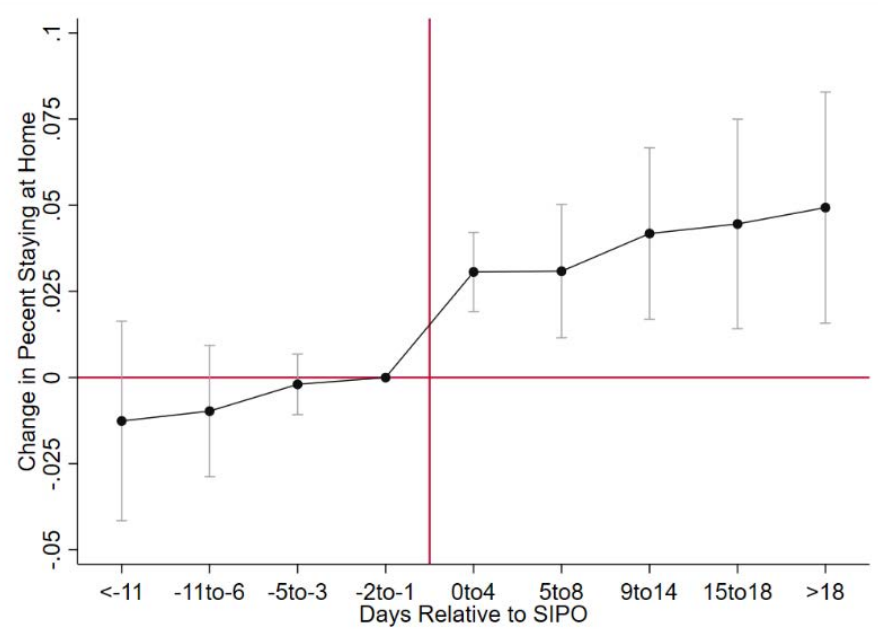


Appendix Table 1: Means of Dependent and independent Variables

Dependent Variables

Percent Staying at Home Full-Time

0.359

Log Case Growth

0.112

$(0.192)$

Independent Variables

SIPO

$\mathrm{NEBCO}^{\mathrm{a}}$

0.039

$(0.194)$

Emergency Declarations

Average Temperature $\left({ }^{\circ} \mathrm{C}\right)$

19.077

(4.768)

Any Precipitation

0.414

$(0.493)$

Notes: Means are weighted using the county population.

${ }^{\text {a }}$ NEBCO denotes a county with a full NEBCO, but without a full SIPO. 


\section{Appendix Table 2: Coefficients on Control Variables for Column (4) of Tables 1 and 2}

\begin{tabular}{lcc} 
& $(1)$ & $(2)$ \\
\cline { 2 - 3 } NEBCO & \% Staying at Home & Case Growth \\
\cline { 2 - 3 } Emergency Order & -0.000 & 0.005 \\
& $(0.003)$ & $(0.023)$ \\
Average Temperature & -0.002 & 0.019 \\
& $(0.004)$ & $(0.020)$ \\
Any Precipitation & $-0.000^{* *}$ & 0.003 \\
& $(0.000)$ & $(0.003)$ \\
$\mathrm{N}$ & $0.006^{* * *}$ & $0.025^{* *}$ \\
& $(0.001)$ & $(0.011)$ \\
\end{tabular}

Notes: Estimates are obtained using weighted least squares regression. The model includes the following controls: an indicator for whether the county had issued a non-essential business closure order, an indicator for whether the county had issued an emergency declaration, the average temperature (in degrees Celsius) in the county, an indicator for whether measurable precipitation fell in the county, county fixed effects, day fixed effects, and a county-specific quadratic time trend. Standard errors, clustered at the county-level, are reported in parenthesis. 


\section{Appendix Table 3: Estimated Effect of SIPOs on COVID-19 Cases in Texas, Including Non-Adopting SIPO States as Controls}

\begin{tabular}{|c|c|c|c|}
\hline & (1) & $(2)$ & (3) \\
\hline \multicolumn{4}{|l|}{ Early-Adopting SIPO Counties } \\
\hline 0-4 Days After & $\begin{array}{c}-0.150 * * * \\
(0.043)\end{array}$ & $\begin{array}{c}-0.116 * * * \\
(0.042)\end{array}$ & $\begin{array}{c}-0.075^{*} \\
(0.039)\end{array}$ \\
\hline 5-8 Days After & $\begin{array}{c}-0.184 * * * \\
(0.058)\end{array}$ & $\begin{array}{c}-0.129 * * * \\
(0.045)\end{array}$ & $\begin{array}{c}-0.102 * * * \\
(0.035)\end{array}$ \\
\hline 9-18 Days After & $\begin{array}{c}-0.210 * * * \\
(0.072)\end{array}$ & $\begin{array}{c}-0.113^{* *} \\
(0.052)\end{array}$ & $\begin{array}{c}-0.098^{* *} \\
(0.041)\end{array}$ \\
\hline$>18$ Days After & $\begin{array}{c}-0.251^{* * *} \\
(0.070)\end{array}$ & $\begin{array}{c}-0.147 * * * \\
(0.048)\end{array}$ & $\begin{array}{c}-0.126 * * * \\
(0.035)\end{array}$ \\
\hline \multicolumn{4}{|l|}{ Late-Adopting SIPO Counties } \\
\hline 0-4 Days After & $\begin{array}{c}-0.031 \\
(0.049)\end{array}$ & $\begin{array}{c}0.013 \\
(0.036)\end{array}$ & $\begin{array}{c}-0.004 \\
(0.030)\end{array}$ \\
\hline 5-8 Days After & $\begin{array}{l}-0.105^{*} \\
(0.058)\end{array}$ & $\begin{array}{l}-0.029 \\
(0.037)\end{array}$ & $\begin{array}{l}-0.042 * \\
(0.025)\end{array}$ \\
\hline 9-18 Days After & $\begin{array}{c}-0.141^{* *} \\
(0.054)\end{array}$ & $\begin{array}{l}-0.063 * \\
(0.034)\end{array}$ & $\begin{array}{c}-0.054^{* *} \\
(0.025)\end{array}$ \\
\hline >18 Days After & $\begin{array}{c}-0.197 * * * \\
(0.061)\end{array}$ & $\begin{array}{c}-0.128 * * * \\
(0.046)\end{array}$ & $\begin{array}{l}-0.076 \\
(0.047)\end{array}$ \\
\hline \multicolumn{4}{|l|}{ Non-Adopting Counties Bound by State SIPO } \\
\hline 0-4 Days After & $\begin{array}{c}-0.030 \\
(0.044)\end{array}$ & $\begin{array}{c}0.016 \\
(0.026)\end{array}$ & $\begin{array}{c}0.002 \\
(0.020)\end{array}$ \\
\hline 5-8 Days After & $\begin{array}{c}0.020 \\
(0.053)\end{array}$ & $\begin{array}{c}0.063 * \\
(0.036)\end{array}$ & $\begin{array}{c}0.031 \\
(0.030)\end{array}$ \\
\hline 9-18 Days After & $\begin{array}{c}0.051 \\
(0.072)\end{array}$ & $\begin{array}{c}0.066 \\
(0.057)\end{array}$ & $\begin{array}{c}0.021 \\
(0.053)\end{array}$ \\
\hline >18 Days After & $\begin{array}{c}0.142 \\
(0.105)\end{array}$ & $\begin{array}{c}0.117 \\
(0.097)\end{array}$ & $\begin{array}{c}0.042 \\
(0.095)\end{array}$ \\
\hline $\mathrm{N}$ & 12954 & 20706 & 45237 \\
\hline Inclusion of Border Non-Adopting SIPO States? & No & Yes & Yes \\
\hline Inclusion of All Non-Adopting SIPO States? & No & No & Yes \\
\hline
\end{tabular}

Notes: Estimates are obtained using weighted least squares regression. The model includes the following controls: an indicator for whether the county had issued a non-essential business closure order, an indicator for whether the county had issued an emergency declaration, the average temperature (in degrees Celsius) in the county, an indicator for whether measurable precipitation fell in the county, county fixed effects, day fixed effects, and a county-specific quadratic time trend. Standard errors, clustered at the county-level, are reported in parenthesis. Counties that adopted SIPO on March 26 or before are defined as EarlyAdopting SIPO Counties, and counties that adopted SIPO between March 27 and April 1 are defined as Late-Adopting SIPO Counties. Border Non-Adopting SIPO states include AR and OK. Other Non-Adopting SIPO states include IA, KY, ND, NC, NE, SD, UT and WY. We excluded Morgan county and Weber county in Utah that adopted a county SIPO on 4/2 from our analysis. 


\section{Appendix Table 4: Estimated Effect of SIPOs on COVID-19 Cases for Other Late Adopting SIPO States (Including All Non-Adopting SIPO States as Controls)}

$\begin{array}{llll}\text { PA } & \text { MO } & \text { FL } & \text { GA }\end{array}$

(1)

(2)

(3)

\section{Early-Adopting SIPO Counties}

0-4 Days After

$\begin{array}{cc}-0.006 & 0.063 \\ (0.029) & (0.056) \\ -0.081 * * & -0.042 \\ (0.035) & (0.043) \\ -0.098 * * * & -0.091 * * \\ (0.032) & (0.041) \\ -0.113 * * * & -0.140 * * * \\ (0.032) & (0.051)\end{array}$

$-0.114 * * *$

$-0.027$

5-8 Days After

(0.035)

(0.028)

$-0.136 * * *$

$-0.085^{* * *}$

9-18 Days After

$$
\text { (0.053) }
$$

$-0.191 * * *$

$-0.088 * * *$

>18 Days After

(0.035)

(0.027)

$-0.157 * * *$

$-0.076$

(0.036)

(0.048)

\section{Late-Adopting SIPO Counties}

0-4 Days After

$\begin{array}{cccc}-0.010 & -0.052 & -0.095^{* * *} & -0.083^{* * *} \\ (0.024) & (0.033) & (0.014) & (0.023) \\ -0.011 & -0.074^{* * *} & -0.128^{* * *} & -0.087^{* * *} \\ (0.018) & (0.016) & (0.017) & (0.020) \\ -0.051^{*} & -0.054 * * & -0.107 * * * & -0.065^{* * *} \\ (0.026) & (0.027) & (0.021) & (0.024) \\ -0.051 & -0.007 & -0.071^{* *} & -0.032 \\ (0.049) & (0.044) & (0.035) & (0.037)\end{array}$

5-8 Days After

9-18 Days After

Non-Adopting Counties Bound by State SIPO

0-4 Days After

$0.075^{* *} \quad 0.040 * *$

$-0.033 * * *$

0.009

(0.031)

(0.015)

(0.013)

5-8 Days After

$0.084 * * *$

0.011

$-0.045 * * *$

$-0.023$

9-18 Days After

(0.031)

(0.020)

(0.016)

(0.017)

0.061

0.008

$-0.042$

$-0.035$

(0.038)

(0.031)

(0.026)

(0.027)

>18 Days After

0.035

$-0.015$

$-0.035$

$-0.076 *$

(0.056)

(0.042)

(0.043)

(0.043)

$\mathrm{N}$

Notes: Estimates are obtained using weighted least squares regression. The model includes the following controls: an indicator for whether the county had issued a non-essential business closure order, an indicator for whether the county had issued an emergency declaration, the average temperature (in degrees Celsius) in the county, an indicator for whether measurable precipitation fell in the county, county fixed effects, day fixed effects, and a county-specific quadratic time trend. Standard errors, clustered at the county-level, are reported in parenthesis. PA counties that adopted SIPO on March 23 or before, MO counties that adopted SIPO on March 25 or before, and GA and FL counties that adopted SIPO on March 26 or before are defined as Early-Adopting SIPO Counties; and PA counties that adopted SIPO between March 24 and April 1, MO counties that adopted SIPO between March 26 and April 6, and GA and FL counties that adopted SIPO between March 27 and April 3 are defined as LateAdopting SIPO Counties. For column (1), PA analysis, we excluded Davis county, Morgan county, Utah county, Wasatch county and Weber county in Utah that adopted a county SIPO on $4 / 1$ or $4 / 2$ from our analysis. 


\section{Appendix Table 5: Calculation of Decomposition of SIPO-Induced Decline in Texas COVID-19 Case Growth}

We utilize equation (5) (with estimates reported in Table 3) to perform the decomposition as follows. First, we compute the actual observed weighted (based on county population) average daily case growth in Texas across all counties and days over our sample period. This observed growth rate (denoted G1) reflects the presence of all SIPOs, localized and statewide, and when they were enacted. Next, we compute the weighted average daily case growth (denoted G2) under the counterfactual scenario wherein no SIPOs at all (either localized or statewide) have been enacted. We do this, based on Equation (5), by netting out the estimated effects of all SIPOs using the estimated coefficients for the three groups of counties from the observed growth rate. The difference $(\mathrm{G} 2-\mathrm{G} 1)$ then represents the average reduction in the daily case growth in the state due to all shelter-in-place orders.

In order to compute how much of this total policy response is driven by the early adopting urbanized counties, we compute the weighted average daily case growth (denoted G3) under another counterfactual scenario such that only the early urbanized jurisdictions adopted their SIPOs, and assume no other SIPOs (later adopters, non-urban counties, or statewide SIPO) have been adopted. To compute this counterfactual growth rate, we subtract out from the observed growth rate the estimated effect of all other SIPOs, except for the early urban localities' orders, utilizing the coefficients estimated reported in Table 3. The difference (G3 G2) represents the reduction in the average daily growth in the state if only the early urban jurisdictions had enacted their orders, and there were no other subsequent orders. Finally, the ratio, [(G3-G2)]/[(G2-G1)], can be interpreted as the percent of the observed growth reduction from the SIPOs that is driven by only the early adopting urbanized county orders. 